\title{
Recent advances in smile designing in prosthodontics
}

\author{
Anita Kapri \\ CL SPL Prosthodontics, Dept. of Prosthodontics, Naval Institute of Dental Sciences, Mumbai, Maharashtra, India
}

Corresponding Author:

Email: a.kapri@rediffmail.com

\begin{abstract}
Confident attractive smile is the most important social bonding gesture and key to your professional enhancement. With the advent of new materials and techniques in the field of esthetic dentistry, people have transformed their idea of smile and how it's designed. In today's era we have digital smile design as a multipurpose digital tool with certain clinically relevant advantages. It has enhanced the esthetic diagnostic capabilities with much more organized treatment plan and better communication among the team members and patient thereby resulting in more predictable treatment outcome and increased effectiveness of case presentation and patient motivation.
\end{abstract}

Keyword: Smile Makeover, Digital Smile Design, Esthetics.

\section{Introduction}

Always make room for more beauty in your life. It is not about being the best but about being better than what we were yesterday. Excellence will never be achieved by chance; rather, it comes from a consistent, systematic approach to diagnosis, communication, treatment planning, and implementation. ${ }^{1}$ To obtain predictable and consistent outcomes, the practitioner should define the design of the restorative treatment at an early stage. The data must guide the succeeding phases of the rehabilitation, scientifically integrating all of the patient's needs and desires and the patient's functional, structural, and biological issues into the esthetic treatment design. The data serve as a frame of reference for the treatment that will be performed. ${ }^{2-4}$ Digital Smile Design in this regard has transformed retrospective excuses into prospective explanations. The incorporation of protocols and checklists for quality control and information management has helped to guarantee that every critical point is performed effectively, is double-checked, and is communicated correctly. ${ }^{5-7}$

\section{Background}

Traditional approach to esthetic smile design includes laminate veneers. The steps in the traditional concept for laminate veneers include taking thorough case history, making a diagnostic impression, mounting with facebow transfer and radiographs include intraoral periapical radiograph and orthopantomogram. A well-adapted, horizontally sectioned silicon matrix made from the diagnostic cast is used as a reference for teeth reduction. ${ }^{8}$ After teeth preparation using depth cut burs a full arch impression is made with rubber base impression materials. Shade selection is done with Vita shade guide (3D Master). The porcelain laminate is processed in the laboratory using either platinum foil technique or refractory die technique. Another conventional approach is two dimensional smile designs as in Fig. 1. Here patient's photographs are placed in MAC Keynote or Powerpoint and a digital two-dimensional designing can be done using the softwares available in the market. This software allows dentists to design new smiles using a simple 2D facial smile photo and intelligent teeth silhouettes. To take care of gingival or pink esthetics the conventional means was to use manual gingival contouring with scalpel and blade as shown in Fig. 2.

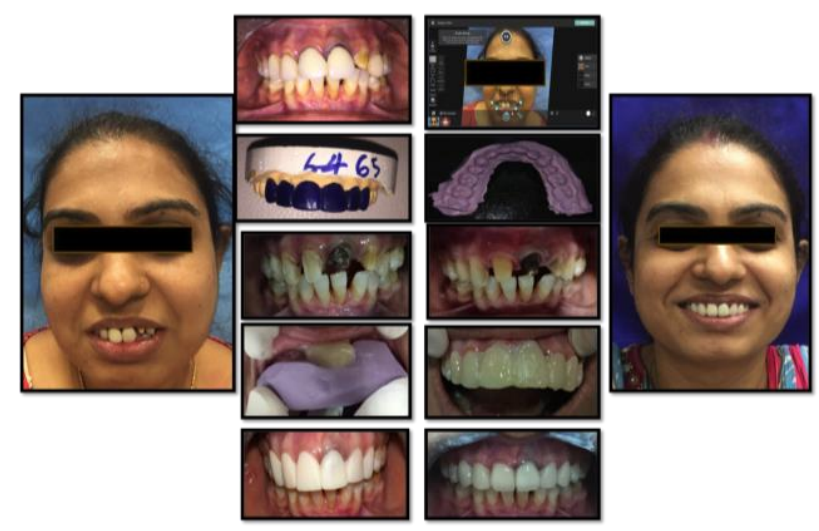

Fig. 1: Traditional digital smile design 


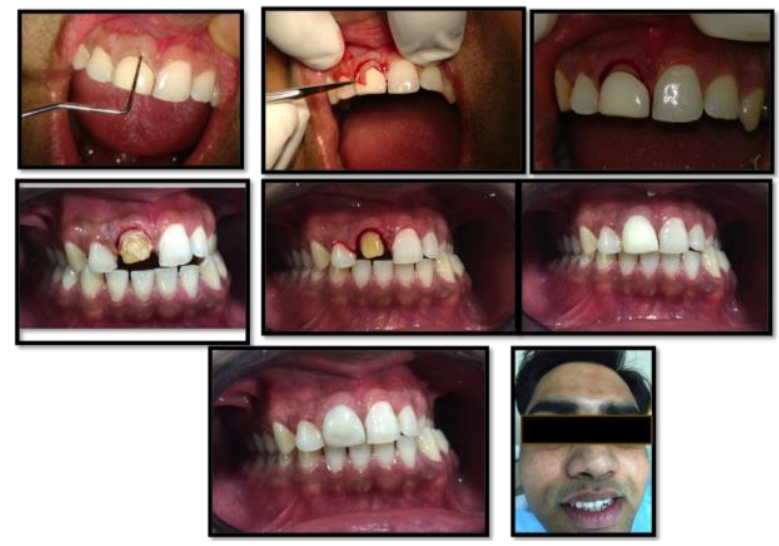

Fig. 2: Traditional gingival contouring

\section{Origin of esthetics in prosthodontics}

In 1936 Wilhem Zech, a master sculptor, had an idea that artificial dentures were something more than porcelain blades adaptable to an edentulous residual ridge. Zech's father was a dentist, and it was for his father that he first began to produce teeth with something more than geometric design. Young Wilhelm Zech, realized that every bone in the human face, as well as throughout the human body, contributes to the total human personality. In 1952, Zech realized that teeth are the instruments of personality and projectors of vitality. Zech experimented with the molders, spacers and arrangement of teeth in artificial dentures for his father. He ground and formed teeth, which by their configuration would depict distinct styles and types of personalities. The soft rounded feminine type; rugged, coarse masculine type. He changed the standard ovoid, square and tapering concepts, and added artistic irregularity of surface along with proximal formation, vigorous ridges and subtle body interpretations.

The Swiss Dent Foundation was established in 1952, in Los Angels, California. Here, ideas were exchanged, photographic results displayed and entire field of dental esthetics was given full emphasis. In a one-day seminar held at Swissdent foundation in 1955, a representative group of about 25 practicing dentists, were handed two well made complete dentures. Everyone was questioned to know whether they belong to man or woman and for what age and personality of the patient do they belong to. Nobody could give specific answers. In contrast, two more dentures were also given to them, one upper denture delicately treated with slight ascending curve to the incisor line and with soft arrangement of teeth. The other was to look at it in the hand, a Grotesque arrangement of craggy teeth, angular and rigidly placed. The first was immediately identified as suitable for a young woman and the second meant for the old man. Frush and Fisher advocated use of appropriate molds for males and females rather than attempting to make a single mold work for both. This produced natural asymmetry. This is how Dentogenics and later dynesthetic concept i.e esthetics in function was introduced..$^{9}$

\section{Discussion}

This paper shall include the concepts of smile design from its origin i.e traditional concepts to the current concept as shown in the flow chart (Table 4).

\section{Table 4: Capabilities of DSD APP}

\begin{tabular}{|l|l|l|}
\hline 1 & $\begin{array}{l}\text { Proper documentation } \\
\text { DSD App Automatic Capture }\end{array}$ & $\begin{array}{l}\text { Helps in taking the picture automatically. } \\
\text { When you hold the iPad in front of your } \\
\text { patient, as soon as the DSDApp recognizes } \\
\text { the best position for the smile design, the } \\
\text { App captures the picture automatically }\end{array}$ \\
\hline 2 & Better motivation & $\begin{array}{l}\text { This app presents a beautiful simulated } \\
\text { smile in a couple of minutes, share with } \\
\text { your patient an emotional presentation and } \\
\text { keep her / his enthusiasm high. }\end{array}$ \\
\hline 3 & Efficient collaboration & $\begin{array}{l}\text { Using the DSD App, we have complete } \\
\text { case management accessibility. We can } \\
\text { organize our case files, add new files at } \\
\text { any time (updated pictures, CBCT, etc), } \\
\text { sort files by date, name, or file format, and }\end{array}$ \\
\hline
\end{tabular}




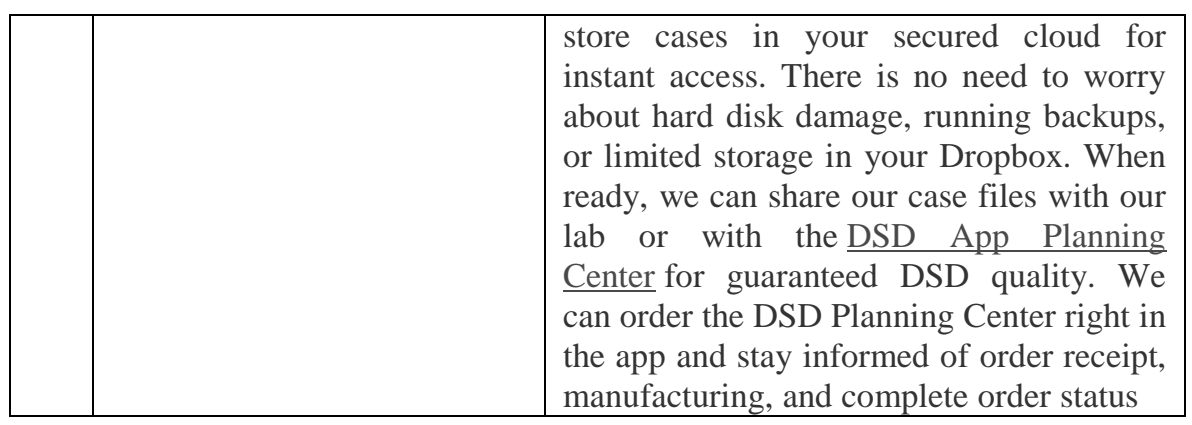

Flow Chart 1

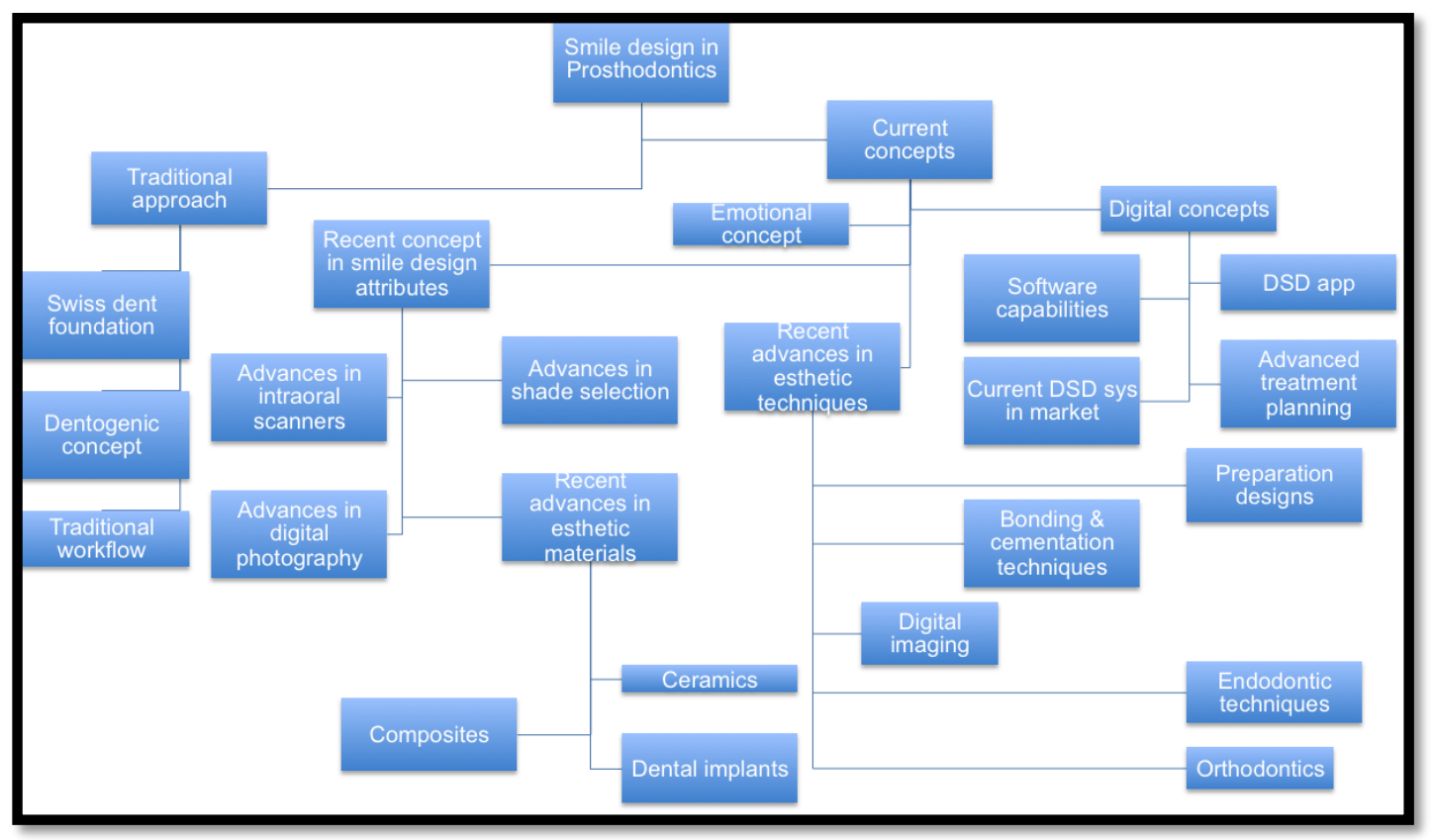

\section{Traditional Concepts: Golden Proportion and RED Proportion}

Creating geometric or mathematical proportion to relate the successive width of maxillary anterior teeth is a critical aspect in Esthetic dentistry. Golden proportion, recurring esthetic dental (RED) proportion and golden percentage are new theories in this field. Both golden proportion and RED proportion were found unsuitable methods to relate the successive width of the maxillary anterior teeth in natural dentition in an in vivo study by Murthy et al. ${ }^{10}$ However, the golden percentage theory can be applied if percentages are adjusted, taking into consideration the ethnicity of the population.

\section{Current Concepts of Smile design; the concept of emotional dentistry}

Patients want beautiful smiles, and also one that is in harmony with their facial characteristics. Emotional Dentistry is analyzing and considering the full face of the patient into the new smile so that it looks natural. Smile design is different from tooth design, with tooth design one is concerned with contour, position and color of individual teeth, while integration of these teeth into the face and facial features is paramount in smile design. The concept of Digital Smile Design (DSD) seeks to present to the world a new face of Dentistry that goes further than traditional dentistry and is emotional and extraordinary. It is also more efficient and precise by using digital technology and multidisciplinary study, further enhancing excellence in dental practice and improving patient satisfaction with results. Digital Smile Design (DSD) is a worldwide recognized scientific concept that has been used for over 8 years by top dental technicians and dentists from all over the world, that improve the quality of aesthetic dental treatments. Digital Smile Design (DSD) is being applied daily as the most cutting-edge technique with an enhanced focus on the patients' emotions and aesthetics. Each design is tailor made to each patient according to their facial and aesthetic features in total harmony with their face, thereby creating a smile that perfectly reflects the personality of each patient. ${ }^{11,12}$

\section{Digital smile design}

Digital Smile Design (DSD) is a multipurpose 
digital tool with clinically relevant advantages. It can strengthen esthetic diagnostic abilities, improve communication among team members, create predictable systems throughout the treatment phases, enhance patients' education and motivation through visualization, and increase the effectiveness of case presentation. Because using DSD can make diagnosis more effective and treatment planning more consistent, the effort required to implement it is worthwhile and will make the treatment sequence more logical and straightforward, saving time and materials and reducing the cost of treatment. ${ }^{1}$

\section{Software Capabilities}

With the help of digital facebow, DSD allows a careful esthetic analysis of the patient's facial and dental features and discovery of many critical factors that might have been overlooked during the clinical, photographic, or study model evaluation. Drawing reference lines and shapes over extra- and intraoral digital photographs in presentation software (such as Keynote [Apple; Cupertino, CA]; PowerPoint [Microsoft; Redmond, WA]; DSD software; or Smile De- signer Pro [Tasty Tech; Toronto, Ontario, CA]), following a predetermined sequence, helps widen the diagnostic vision. This visualization process also helps the team to assess and understand limitations and risk factors such as asymmetries, disharmonies, and esthetic principle violations, adding critical data to the process of treatment planning. ${ }^{13}$ Choosing the appropriate technique is easier once problems have been identified and the solution clearly visualized. It also helps calibrating the intraoral photograph to the facial photograph, tooth proportion analysis. There are various tooth libraries based on the morphopsychology of the patient. The digital ruler helps in measuring the gingival and incisal discrepancies for treatment planning and for guiding the wax-up. Virtual Articulator and occlusal analysis helps detecting occlusion and mesiodistal or buccolingual space discrepancies. DSD drawings aid in better understanding the space management possibilities, implant position, and horizontal ridge reconstruction.

\section{Treatment Planning}

With the help of virtual mockups, a previsualization therapy planning is ensured and a twodimensional data is matched to three-dimensional data resulting in virtual previsualization. This helps in better patient, technician, and interdisciplinary communication, a better feedback, case presentation and education.

\section{DSD App}

DSD App founded by Dr Christian Cachman for iphone and ipad users is a Digital Smile Design software, designed to successfully improve your case acceptance and to motivate your patient on their first visit. Dr Christian Coachman quotes "After a decade of hard work to develop a pragmatic, efficient and artistic system for facial

Analysis, Esthetic Diagnosis and Smile Design in accordance with the most modern concepts of natural esthetics, I'm proud to present this new, simple to use but powerful tool, based on the latest mobile and cloud technologies-DSDApp - that will allow dentists, technicians, specialists, plastic surgeons and staff members to create beautiful smiles, to communicate, to present attractive projects and enchant their patients". The capabilities of DSD App have been listed in Table 5.14

\section{DSD in Market}

Seven DSD Systems are available in the market currently namely CEREC Smile Design (SIRONA), Digital Smile Design (DSD), Digital Smile System (DSS), G Design (HACK DENTAL), Romexis Smile Design (PLANMECA), Smile Composer (3 SHAPE) and Smile Design Pro (TASTY TECH).

\section{Current concepts of smile design attributes \\ Recent advances in digital photography: Extraoral} Video Camera takes photograph of patient while moving or talking so that various moods and gestures can be captured and give details, which even the patient, is unaware. Latest Intraoral camera is the revolutionary "patient conversation starter." The camera's unique liquid lens technology works like the human eye to ensure effortless image capture to deliver clear, detailed images patients can really understand. Featuring high still image resolution, the Camera ensures "picture perfect" shots each and every time. The Duo Cam is a Dental Camera Technology Breakthrough as it takes both the highest resolution Intraoral images and also takes Extraoral pictures for your Cosmetic, Dental examinations and Patient Communication needs.

Recent advances in shade selection: Colorimeter, spectrophotometer, spectroradiometer and digital cameras have changed the way a shade selection used to be done. All these devices have made subjective color analysis to objective color analysis and with no influence of the external environment. Colorimeter is the instrument that combines digital color analysis with colorimetric analysis. It consists of a hand-held device with its own light source, and an LCD screen facilitates positioning on the tooth. Spectrophotometer is the only one that combines digital color imaging with spectrophotometric analysis. A digital image of the tooth, the shade mapping, and the colorimetric data can be transmitted to the laboratory electronically or by printout. Hand-held spectro-photometer consists of a hand piece connected to a base unit by a monocoil fiber optic cable assembly. The contact probe tip is approximately $5 \mathrm{~mm}$ in diameter he tooth is illuminated by the periphery of the tip, directing the light from a 
halogen bulb in the base unit into the tooth surface. There are several spectrometers in the hand piece that monitor the light source and measure the internally scattered light. The display presents the closest Vita shade in the classical or 3D shade guide designation. ${ }^{15}$ Through this arrangement, spectral reflectance of the scattered light is essentially measured in $25 \mathrm{~nm}$ bandwidths. Digital cameras capture images using CCDs, which contain many thousands or even millions of6microscopically small light-sensitive elements (photosites). Like the photodiodes, each photosite responds only to the total light intensity that strikes its surface.

\section{Recent advances in intraoral scanners ${ }^{16}$}

Currently available two-dimensional intraoral scanners are listed in Table 1. The introduction of threedimensional intraoral scanners has changed the face of traditional dental laboratory dependent dental clinics (Table 2). It's a total plaster or stone free dentistry now. All the disadvantages associated with plaster models are alleviated. Latest intraoral 3D scanners are listed in Table 3 .

Table 1: Currently available intraoral scanners

\begin{tabular}{|c|c|c|c|}
\hline 1 & $\begin{array}{l}\text { CERECs - by sirona dental system } \\
\text { GmbH (Germany) }\end{array}$ & 8 & $\begin{array}{l}\text { Bluescans -I - ATRON3Ds GmbH } \\
\text { (Austria) }\end{array}$ \\
\hline 2 & iTero - by cadent Ltd (Israel) & 9 & $\begin{array}{l}\text { DPI-3D - by dimensional photonics } \\
\text { international,Inc. (USA) }\end{array}$ \\
\hline 3 & iTero - by cadent Ltd (Israel) & 10 & $\begin{array}{l}\text { DPI-3D - by dimensional photonics } \\
\text { international,Inc. (USA) }\end{array}$ \\
\hline 4 & $\begin{array}{l}\text { E4D - by D4D technologies, Llc } \\
\text { (USA) }\end{array}$ & 11 & $\begin{array}{l}\text { 3D Progress - by MHT S.p.A. (Italy) } \\
\text { and MHT optic research AG } \\
\text { (Switzerland }\end{array}$ \\
\hline 5 & $\begin{array}{l}\text { LavaTMC.O.S. - by } 3 \text { M ESPE } \\
\text { (USA) }\end{array}$ & 12 & $\begin{array}{l}\text { directScan - by hint - ELS GmbH } \\
\text { (Germany) }\end{array}$ \\
\hline 6 & $\begin{array}{l}\text { IOS FastScan - by IOS } \\
\text { TECHNOLOGIES, Inc. (USA) }\end{array}$ & 13 & trios - by 3 shape A/S (Denmark) \\
\hline 7 & $\begin{array}{l}\text { MIA3dTM - by Densys3D Ltd } \\
\text { (Israel) }\end{array}$ & & \\
\hline
\end{tabular}

Table 2: Three-dimensional Intraoral Scanners

\begin{tabular}{|l|l|}
\hline \multicolumn{2}{|l|}{ Overcome Disadvantages } \\
\hline 1 & Mould instability; \\
\hline 2 & Mould transport and packaging; \\
\hline 3 & Pouring and solidification; \\
\hline 4 & Delamination; \\
\hline 5 & Lacerations on margins; \\
\hline 6 & Contact between the tray and the teeth; \\
\hline 7 & $\begin{array}{l}\text { Geometrical and dimensional } \\
\text { inconsistencies between the plaster } \\
\text { model and the real teeth }\end{array}$ \\
\hline Advantages \\
\hline 1 & More accurate models; \\
\hline 2 & Workflow simplification; \\
\hline 3 & create and periodically update a database \\
\hline 4 & $\begin{array}{l}\text { Possibility to simulate surgery } \\
\text { interventions on the digital model; }\end{array}$ \\
\hline 5 & $\begin{array}{l}\text { Reduced work hazard for technician and } \\
\text { dentist }\end{array}$ \\
\hline
\end{tabular}

Table 3: Latest 3 D Scanners

\begin{tabular}{|c|l|}
\hline 1 & Planscan - Planmeca Oy (Finland) \\
\hline 2 & Condor - Remedent Inc. (Belgium) \\
\hline 3 & $\begin{array}{l}\text { CS 3500 - Carestream Health, Inc. } \\
\text { (USA) }\end{array}$ \\
\hline 4 & $\begin{array}{l}\text { DigImprint - Steinbichler Optotechnik } \\
\text { GmbH (Germany) }\end{array}$ \\
\hline
\end{tabular}


Transition from traditional digital workflow to rapid digital workflow

According to the state of the art, there are three kinds of workflows in restorative dentistry. The traditional workflow, which is the oldest wherein the dentist makes, the impression and then a stone model is poured. The stone model is scanned in the laboratory then designing and milling is carried out. Sometimes the plaster pouring can be skipped because the impression tray is directly scanned. This second kind of workflow is the 'former digital workflow'. The term 'former' is used to distinguish this method from the newest one that is 'rapid digital workflow'. The third kind of workflow is the rapid digital workflow. This workflow can be followed when the clinician owns an intraoral scanner equipped with an in-office milling unit, The dentist captures the digital impression by means of an intraoral scanning device; the dentist designs the restoration and the software automatically generates the program for the milling unit; the final restoration is milled in a few minutes; the doctor applies the restoration.

\section{Recent advances in esthetic materials and techniques}

Prefabricated Composite Veneers ${ }^{17}$ : Veneering anterior teeth is a well-established technique, which was brought to Dentistry by Dr Pincus as early as 1937 . From the mid-1970s, the prefabricated composite veneer option was however soon abandoned due to former technological limitations. Recently, the creation of a new shade guide comprising enamel shells revitalized this "old idea," and in combination with a high pressure and temperature molding process followed by a laser surface vitrification, a novel, improved composite prefabricated system is introduced.
Indirect Composite Veneers ${ }^{18}$ : Initially the composite veneers were fabricated in the dental laboratory using light cure unit and now with the availability of CADCAM composite blocks have made possible the indirect fabrication using CADCAM. ${ }^{19}$

Direct Composites: Nanofillers, Ormocers, Giomers and Silorane have improved the mechanical as well as esthetic properties of direct composite resin thereby enchanicing its usage for smile design purposes.

Preparation Designs: Incisal Overlap still is used as a promising preparation design for esthetic veneers. Tooth preparation through Aesthetic Previsualization Temporaries (APT) using depth cutter burs at 3 different angulations to achieve accurate depth ensures a more minimally invasive technique for laminate preparation. ${ }^{20}$ Lumineers a special brand of laminates were introduced lately, which requires little or no preparation (preparation as thin as contact lens).

\section{Recent advances in ceramics}

Dental Ceramics have come a long way from YTZP Zirconia ceramics to CADCAM, which ensured its usage for three unit bridges too. CEREC 1, CEREC 2, CELAY, CEREC 3 and now CEREC 3D System is introduced. The subtractive milling has reached till the level of five-axis milling. Introduction of additive milling have reduced the disadvantages associated with subtractive milling like the material loss.

\section{Smile design with dental implants}

Esthetic means of ensuring smile design in implants are gingival contouring, ridge augmentation, various provisionals, customized abutments and gingival formers with the biggest breakthrough being Zirconia abutments as shown in Fig. 3.
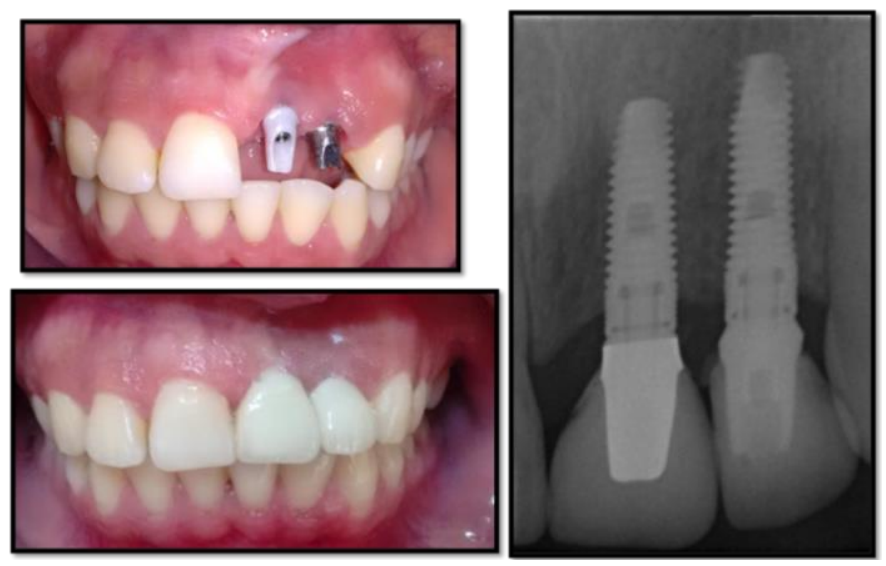

Fig. 3: Zirconia Abutment

\section{Smile design in endodontics and orthodontics}

Prefabricated or custom made zirconia post as shown in Fig. 4 under an all ceramic core giving a monoblock effect have actually shown superior esthetics especially vs gold or fiber post as it is difficult to mask the gingival hue of discolored dentin in thin gingival type. Invisalign clear aligners and ceramic brackets have changed the face of orthodontic smile design. 

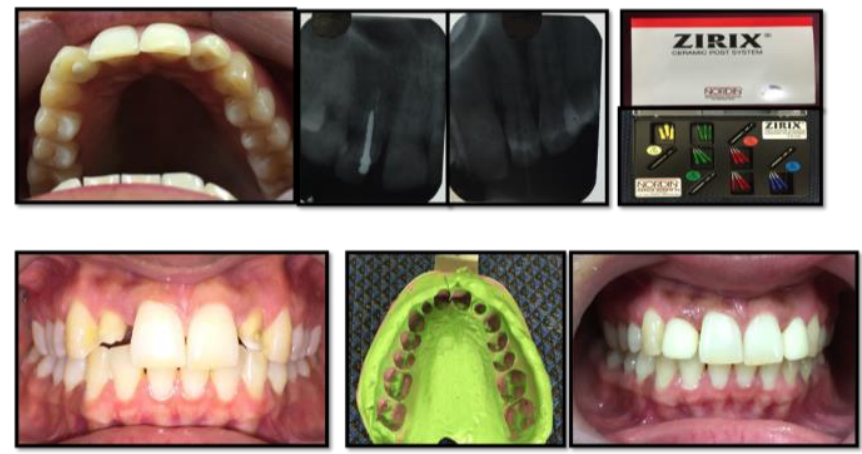

Fig. 4: Zirconia post steps of fabrication

\section{Bleaching and abrasive techniques}

With the advent of photo assisted bleaching with Lasers and LED especially Argon laser of 488nm KTP or $532 \mathrm{~nm}$, bleaching is now become photochemical. Blue LED $472 \mathrm{~nm}$ is used. Titanium oxide nanoparticle based catalyst is used so Hydrogen peroxide is reduced so there is less sensitivity. There are various means of bleaching like whitning strips, paste, gels and rinses etc.

\section{Bonding and cementation}

We have reached a Seventh Generation bonding era, which is single component one step self etch, adhesive. A Universal Adhesive for both the tooth \& ceramic is also introduced. Color change after cementation should also be taken into account while cementing. Panavia is best as it contains MDP for bond with latest. When we are working with laminates light cure is best as dual cure resin may not give enough workability.

\section{Advances in digital imaging}

With the advances in digital imaging and threedimensional printers, it is possible to fabricate a fully digitized surgical navigation system with a three printed CADCAM stent after integrating the digital impression scan data with the CBCT data as shown in Fig. 5, thereby ensuring correct placement and angulation of implant with minimal invasion and less pain.

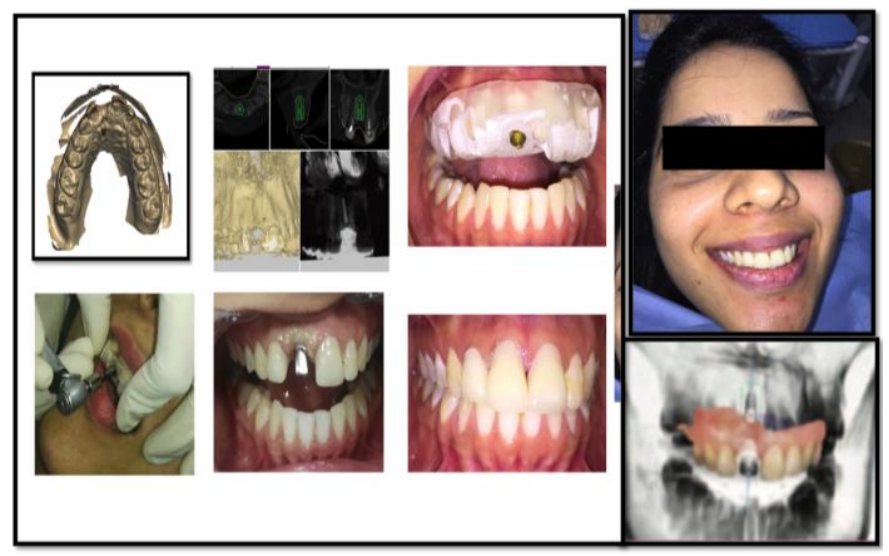

Fig. 5: Anterior implant esthetics with digital navigation with simulated final outcome

\section{Conclusion}

This article makes a novel attempt to summarize the current concepts in smile design in prosthodontics in a systematic manner. Ideal Smile is what makes the person happy. Recommendations include that DSD should be used as an auxillary tool because beauty lies in the eyes of the beholder and ultimately mimicking the nature always works best. With advances in digital dentistry including the dental materials and techniques and usage of the recent concepts of smile design in prosthodontics highlighted in this article appears to provide encouraging results and predictable outcome.
Funding: No funding sources.

Conflict of interest: None declared.

\section{References}

1. Christian Coachman, Marcelo A Calamita; Virtual Esthetic Smile Design; Driving the restorative plan; $J$ Cosmetic Dent 2014;29(4).

2. Dawson PE. Functional occlusion: from TMJ to smile design. St. Louis: Mosby; 2007.

3. Spear FM. The maxillary central incisor edge: a key to esthetic and functional treatment planning. Compend Contin Educ Dent 1999;20(6):512-6.

4. Kois JC. Diagnostically driven interdisciplinary treatment planning. ?

5. Coachman C, Van Dooren E, Gürel G, Landsberg CJ, Calamita MA, Bichacho N. Digital smile design: from 
digital treatment planning to clinical reality. In: Cohen $\mathrm{M}$, editor. Interdisciplinary treatment planning, Vol. II: comprehensive case studies. Hanover Park (IL): Quintessence; 2011.

6. Goldstein RE. Esthetics in dentistry: principles, communication, treatment methods. Hamilton (ONT): Decker; 1998.

7. Chiche GJ, Pinault A. Esthetics of anterior fixed prosthodontics. Hanover Park (IL): Quintessence; 1996.

8. Harleen Sachdeva, Sumit Khare, Rama Shankar, Nishit Kumar; Porcelain Laminates Veneers: Case Report, J Res Adv Dent 2015;4:2:16-20.

9. Anju Rajashekhar, Deviprasad Nooji, Manoj Kumar; Chapter 3 History of Dentogenics. In Dentogenics in Complete Denture Prosthodontics; LAP Lambert Academic Publishing. 2015;7-9

10. BV Sreenivasan Murthy, Niketa RamaniEvaluation of natural smile: Golden proportion, RED or Golden percentage. J Conserv Dent 2008;11(1)

11. Anne E. Beall; Can a new smile make you look more intelligent and successful. Dent Clin N Am 2007;51:28997.

12. Arpit Sikri, Vidhushi Saxena; Smile Design - The concept of Emotional Dentistry; Lambert Publishing; July 28,2017

13. Coachman C, Van Dooren E, Gürel G, Landsberg CJ, Calamita MA, Bichacho N. Digital smile design: from digital treatment planning to clinical reality. In: Cohen M, editor. Interdisciplinary treatment planning, Vol. II: comprehensive case studies. Hanover Park (IL):
Quintessence; 2011.

14. Coachman C, Digital Smile Design App [Internet] DSD technology 2018 [cited 11 Mar 2018] Available from: https://www.digitalsmiledesignapp.com/pricing

15. Smitha AJ, Savitha PN; Shade Matching in Aesthetic Dentistry - From Past to Recent Advances. J Dent Oral Care Med 3(1):1-10.

16. Silvia Logozzo a,n, Elisabetta M. Zanetti a, Giordano Franceschini a, Ari Kilpelä b, Anssi Mäkynen b, Recent advances in dental optics - Part I: 3D intraoral scanners for restorative dentistry; Optics and Lasers in Engineering 2014;54:203-21

17. Didier Dietschi, Alessandro Devigus; Prefabricated Composite Veneers: Historical Perspectives, Indications and Clinical Application. Eur J Esthetic Dent 2011;6(2).

18. Mainjot AK, Dupont NM, Oudkerk JC, Dewael TY, Sadoun MJ. From Artisanal to CAD-CAM Blocks: State of the Art of Indirect Composites. J Dent Res 2016;95(5):487-95. Epub 2016.

19. Sasipin Lauvahutanon et al; Mechanical properties of Composite resin blocks for CADCAM ; Dent Materials $J$ 2014;33(5):705-10.

20. Predictable And Precise Tooth Preparation Techniques For Porcelain Laminate Veneers In Complex Cases Galip Gürel; International Dentistry Sa 9(1):1-7.

How to cite the article: Kapri A. Recent advances in smile designing in prosthodontics. Ann Prosthodont Restor Dent 2018;4(3):60-67. 